\title{
Nocturic Episodes in Patients with Benign Prostatic Enlargement May Suggest the Presence of Obstructive Sleep Apnea
}

\author{
Howard Tandeter, MD, Sammy Gendler, Jacob Dreiber, MD, MPH, and \\ Ariel Tarasiuk, $P h D$
}

Background: Nocturia is a common symptom of benign prostatic enlargement (BPE) that is generally attributed to a urologic pathology. This study assessed whether nocturia severity in BPE patients may be related to an underlying sleep disorder.

Methods: Cross-sectional study based in urban community primary care clinics. Study population included men aged 55 to 75 years old. The research group included patients with documented BPE and nocturia of at least once per night versus a comparison group without BPE and with either no or one nocturia episode per night. The presence of symptoms of obstructive sleep apnea (SOSA) was assessed using the Berlin questionnaire.

Results: Patients with BPE were significantly more likely to report weight gain (21\% vs $10 \%)$, loudness of snoring $(22.6 \%$ vs $4 \%)$, daytime sleepiness (35.3\% vs $12.0 \%)$, and hypertension $(61.8 \%$ vs 41.0\%). Fifty-nine patients $(\mathbf{5 7 . 8 \%})$ in the research group were considered high risk for OSA compared with 31 patients $(31.0 \%)$ from the comparison group $(P<.001)$. The odds ratio $(0 R)$ for SOSA gradually increased from 1.00 in patients reporting no nocturia to $2.44,5.75$, and 12.3 in patients reporting 1,2 to 3 , and $>3$ episodes of nocturia per night, respectively.

Conclusion: The odds for SOSA increased log-linearly in correlation with the number of nocturia episodes. We imply that nocturic episodes in patients with BPE may suggest the presence of OSA. Physicians following patients with BPE who report frequent awakenings from sleep to urinate should suspect OSA as a possible comorbidity. (J Am Board Fam Med 2011;24:146-151.)

Keywords: Benign Prostatic Enlargement, Nocturia, Primary Care, Obstructive Sleep Apnea, Sleep Disorders

Nocturia has been defined by the International Continence Society as "the complaint that the individual has to wake up at night one or more times

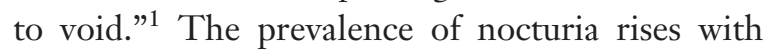
age, from $3.4 \%$ in men younger than 20 up to $32.4 \%$ in men older than 60 . Approximately $10 \%$ of the general population older than 20 wakes up at

This article was externally peer reviewed.

Submitted 5 May 2010; revised 7 September 2010; accepted 14 September 2010.

From the Faculty of Health Sciences, Siaal Research Center for Family Medicine and Primary Care (HT, JD); the Department of Family Medicine, Ben Gurion University of the Negev (HT, JD, AT); Clalit Health Services (HT, JD).

Funding: none.

Conflict of interest: none declared.

Corresponding author: Howard Tandeter, MD, Department of Family Medicine, Faculty of Health Sciences, BenGurion University of the Negev, PO Box 653, Beer-Sheva (84105), Israel (E-mail: howard@bgu.ac.il). least 2 times or more per night to urinate. ${ }^{2}$ Nocturia has been found to be a common reason for interrupted sleep among the adult population and has a negative impact on quality of life, affecting both morbidity and mortality. The etiology of nocturia falls into 3 categories: diurnal polyuria (diabetes mellitus, diabetes insipidus, primary polydipsia, hypercalcemia); nocturnal polyuria (congestive heart failure, renal insufficiency, excessive intake of fluid at night, venous insufficiency, edema, hypoalbuminemia, use of diuretics); and low bladder capacity (urinary tract infection, benign prostatic hypertrophy $[\mathrm{BPH}]$ or prostatic cancer, and overactive bladder). ${ }^{3}$

Data accumulated in recent years show that nocturia may be related to obstructive sleep apnea (OSA). A retrospective review of clinical and laboratory polysomnographic data revealed that noctu- 
ria is common among patients with OSA. ${ }^{4}$ OSA has been found to be an independent cause of frequent urination during sleep among elderly men. ${ }^{5}$ Use of a continuous positive airway pressure machine has been found to be an effective treatment for nocturia associated with OSA. ${ }^{6}$

Nocturia is a common symptom of benign prostatic enlargement (BPE)/BPH and, when found in patients with $\mathrm{BPE} / \mathrm{BPH}$, it is generally attributed to the urologic pathology without looking for other possible explanations. We hypothesize that nocturia severity among patients with BPE may be related to an underlying sleep disorder (OSA) and not solely to the urologic problem. Because BPE is a common problem in primary care, the present study was design to test whether primary care patients with nocturia attributed to BPE may, in fact, have a higher prevalence of symptoms of OSA (SOSAs), which may explain nocturnal waking to void.

\section{Materials and Methods}

\section{Setting}

This cross-sectional study was held in 2 primary care clinics of Clalit Health Services (the largest health care provider organization in Israel) in the city of Beer Sheva. The population of these clinics is estimated at 25,000 patients; $48 \%$ of them are men. Adult patients in both clinics are under the care of 12 board-certified family physicians.

\section{Study Population}

This study cohort included men between the ages of 55 and 75 years who were randomly sampled from the primary care clinics and who had been diagnosed with BPH (according to the electronic medical record) and reported nocturia at least once per night (Figure 1). To obtain a random sample, the computer system at Clalit Health Services uses an algorithm based on the patients' diagnoses, the age/sex of the patients, and the number of patients needed. Although we searched for a diagnosis of $\mathrm{BPH}$ in our medical records, this actually reflects the presence of BPE. For a diagnosis of $\mathrm{BPH}$ to appear in our electronic medical records, patients who present with symptoms suggestive of BPE are seen and diagnosed at least once by an urologist (including digital rectal examination) after undergoing renal function tests, urine cytology and culture, a prostatic-specific antigen test, and an ultra-
Figure 1. Flow chart showing the data collecting process for the research group (A) and comparison group (B). BPH, benign prostatic hypertrophy.
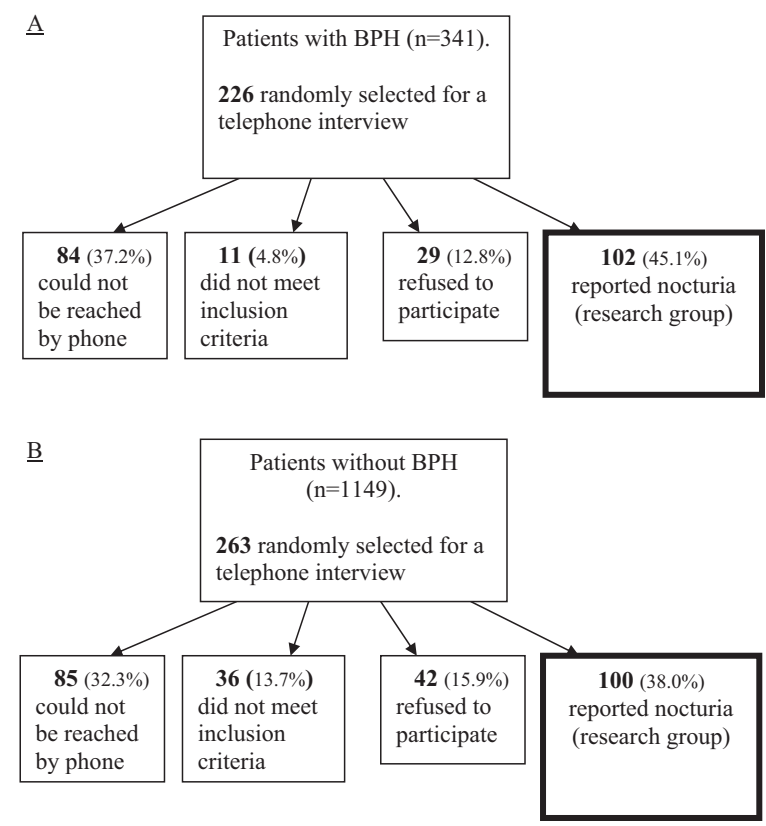

sound of the urinary tact and prostate gland to exclude other pathologies that may explain patient's symptoms. Because histologic diagnosis is not performed for these patients, the proper diagnosis should be BPE and not BPH. The comparison group included patients who did not have a diagnosis of BPH/BPE and who reported no nocturia or "mild nocturia" (once per night). Patients with a diagnosis of OSA in their medical record were excluded. Data were collected from 202 participants (102 in the research group and 100 in the comparison group). The Institutional Ethics Committee approved the protocol.

\section{Questionnaire}

SOSAs were assessed using the Berlin questionnaire, the efficiency of which has been proved and established in several different studies. ${ }^{4-6}$ The questionnaire was translated and validated to the Hebrew language. Patients were grouped into either a "high risk for OSA" group or a "low risk for OSA" group, according to the calculated score.

\section{Data Collection and Procedure}

Patients completed the Berlin Questionnaire via telephone. The interviewer introduced himself and asked the patient's approval to answer the question- 
naire. Data collection occurred from January 2007 through March 2008.

\section{Statistical Analysis}

Data analysis was performed using SPSS software (version 12.0.2, SPSS, Inc., Chicago, IL). Patients' characteristics, answers to the questionnaire items, and the risk grouping for SOSAs are presented using proportions for categorical variables and means and SDs for continuous variables. The association between pairs of categorical variables was tested using the $\chi^{2}$ test, whereas association between categorical and continuous variables was assessed using $t$ tests and analysis of variance. In all tests, $P<.05$ was considered to be statistically significant. The association between the level of nocturia (episodes of nocturia per night) and the presence of SOSAs, according to the questionnaire results, and the different risk groups was assessed using odds ratios (OR) and 95\% CI. The null hypothesis was rejected at the $5 \%$ level.

\section{Results}

Figure 1 shows the data collection process. From the population of the 2 primary care clinics we produced a list of patients who had been diagnosed with BPH/BPE (341 patients), of whom 226 were randomly sampled. One-hundred and two patients (45.1\%) of the 226 sampled matched the inclusion criteria for the study and were willing to participate. Eighty-four patients could not be reached by phone, 11 did not meet inclusion criteria, and 29 refused to participate. The comparison group included 1149 patients, of whom 263 were randomly sampled. One hundred patients $(38.0 \%)$ met inclusion criteria for the study and agreed to participate, whereas 85 patients could not be reached by phone, 36 failed to meet inclusion criteria, and 42 refused to participate.

Patients' mean age was $65.9 \pm 5.8$ years and $65.8 \pm 4.8$ years in the in the research and comparison groups, respectively $(P=.769)$. Mean body mass index (BMI) in the research group was $26.4 \pm$ $3.6 \mathrm{~kg} / \mathrm{m}^{2}$ and $27.3 \pm 4.4 \mathrm{~kg} / \mathrm{m}^{2}$ in the research and comparison groups, respectively $(P=.114)$.

Among the patients in the research group, 27 $(26.4 \%)$ reported nocturia once per night, 58 (56.8\%) reported nocturia 2 to 3 times per night, and $17(16.6 \%)$ reported nocturia $>3$ times per night. Among the patients in the comparison group, 43 (43\%) reported that they do not suffer from nocturia, and 57 (57\%) reported nocturia only once per night.

Symptom frequencies are presented in Table 1. Patients were grouped into a "high risk for SOSAs" group and a "low risk for SOSAs" group according to the calculated score. Among the research group, 59 patients $(57.8 \%)$ were considered to have a high risk for SOSAs, opposed to only 31 patients $(31.0 \%)$ from the comparison group (OR, 3.05; $95 \%$ CI, 1.71-5.44) (Table 2). Thus, $65.6 \%$ of the high-risk group, compared with $38.4 \%$ of the lowrisk group, were from the research group.

When the study population was divided according to risk groups (disregarding the initial orientation of research/comparison groups), patients from the high-risk group had higher BMI values (28.3 vs 25.6; $P<.001)$ but a similar age distribution $(66.2 \pm 5.3$ years vs $65,7 \pm 5.3$ years; $P=.749)$. The proportion of patients in the high-risk group increased in a log-linear trend as the number of nocturia episodes per night increased. The odds for a high risk of SOSA (defined as 1.00 for patients without nocturia) increased in a dose-response pattern, from OR, 2.44 (95\% CI, 1.03-5.75) among patients who reported one episode of nocturia per night to OR, 5.75 (95\% CI, 2.32-14.2) for those reporting 2 to 3 episodes of nocturia per night, to OR, 12.3 (95\% CI, 3.21-46.9) among those reporting $>3$ episodes of nocturia per night (Figure 2).

\section{Discussion}

Roger von Oech wrote, "Life is ambiguous; there are many right answers, all depending on what you are looking for. But if you think there is only one right answer, then you'll stop looking as soon as you find one."7 Physicians often do this during continued patient care: they stop looking for other possible answers to a problem as soon as they find one that seems to be correct. ${ }^{8}$ In the present study we found that patients who had been diagnosed with BPE and who complain of nocturic episodes had a higher probability of reporting high risk for SOSAs (a higher Berlin Questionnaire score). Each additional episode of nocturia per night increased the OR for having a high risk for SOSAs by 2.44 in a log-linear pattern. In these cases, after a diagnosis of BPE and after follow-up by an urologist began, the primary care physician stopped looking for another possible answer for patients' nocturia. The 
Table 1. Distribution of the Questionnaire Results by Study Groups.

\begin{tabular}{|c|c|c|c|}
\hline Questions & $\begin{array}{c}\text { Comparison Group } \\
(\mathrm{n}=100)\end{array}$ & $\begin{array}{l}\text { Research Group } \\
\quad(\mathrm{n}=102)\end{array}$ & $P$ \\
\hline \multicolumn{4}{|l|}{ Screening Question } \\
\hline \multicolumn{4}{|c|}{ Do you wake up at night in order to urinate? } \\
\hline No & $43(43.0)$ & $0(0)$ & \multirow{4}{*}{$<.001$} \\
\hline Once & $57(57.0)$ & $27(26.5)$ & \\
\hline 2-3 times per night & $0(0)$ & $58(56.9)$ & \\
\hline$>3$ times per night & $0(0)$ & $17(16.7)$ & \\
\hline \multicolumn{4}{|l|}{ Berlin Questionnaire } \\
\hline Has your weight changed & & & \\
\hline Increased & $10(10.0)$ & $22(21.6)$ & \multirow{3}{*}{.049} \\
\hline Decreased & $20(20.0)$ & $13(12.7)$ & \\
\hline No change & $70(70.0)$ & $67(65.7)$ & \\
\hline \multicolumn{4}{|l|}{ Do you snore? } \\
\hline Yes & $51(51.0)$ & $61(59.8)$ & \multirow{3}{*}{.291} \\
\hline No & $38(38.0)$ & $35(34.3)$ & \\
\hline Do not know & $11(11.0)$ & $6(5.9)$ & \\
\hline \multicolumn{4}{|c|}{ Snoring loudness $(\mathrm{n}=103)^{*}$} \\
\hline As loud as breathing & $5(10.0)$ & $9(17.0)$ & \multirow{4}{*}{.019} \\
\hline As loud as talking & $31(62.0)$ & $24(45.3)$ & \\
\hline Louder than talking & $12(24.0)$ & $8(15.1)$ & \\
\hline Very loud & $2(4.0)$ & $12(22.6)$ & \\
\hline \multicolumn{4}{|c|}{ Snoring frequency $(\mathrm{n}=109)^{*}$} \\
\hline Almost every day & $17(33.3)$ & $27(46.6)$ & \multirow{4}{*}{.261} \\
\hline 3-4 times/week & $30(58.8)$ & $25(43.1)$ & \\
\hline $1-2$ times/month & $4(7.8)$ & $6(10.3)$ & \\
\hline Never or almost never & $0(0)$ & $0(0)$ & \\
\hline \multicolumn{4}{|c|}{ Does your snoring bother other people? $(\mathrm{n}=112)^{*}$} \\
\hline Yes & $18(35.3)$ & $30(49.2)$ & \multirow[t]{2}{*}{.180} \\
\hline No & $33(64.7)$ & $31(50.8)$ & \\
\hline \multicolumn{4}{|c|}{ How often have your breathing pauses been noticed? $(n=199)$} \\
\hline Almost every day & $0(0)$ & $1(1.0)$ & \multirow{4}{*}{.389} \\
\hline 3-4 times/week & $7(7.1)$ & $4(4.0)$ & \\
\hline $1-2$ times/month & $6(6.1)$ & $3(3.0)$ & \\
\hline Never or almost never & $86(86.9)$ & $92(92.0)$ & \\
\hline \multicolumn{4}{|c|}{ Are you tired after sleeping? $(\mathrm{n}=201)$} \\
\hline Almost every day & $12(12.0)$ & $19(18.8)$ & \multirow{4}{*}{.215} \\
\hline 3-4 times/week & $11(11.0)$ & $18(17.8)$ & \\
\hline 1-2 times/month & $10(10.0)$ & $8(7.9)$ & \\
\hline Never or almost never & $67(67.0)$ & $56(55.4)$ & \\
\hline \multicolumn{4}{|c|}{ Are you tired during the time you are awake? } \\
\hline Almost every day & $12(12.0)$ & $36(35.3)$ & \multirow{4}{*}{$<.001$} \\
\hline 3-4 times/week & $25(25.0)$ & $24(23.5)$ & \\
\hline 1-2 times/month & $16(16.0)$ & $6(5.9)$ & \\
\hline Never or almost never & $47(47.0)$ & $36(35.3)$ & \\
\hline \multicolumn{4}{|c|}{ Have you ever fallen asleep while driving? } \\
\hline Yes & $3(3.0)$ & $6(5.9)$ & \multirow[t]{2}{*}{.498} \\
\hline No & $97(97.0)$ & $96(94.1)$ & \\
\hline \multicolumn{4}{|c|}{ Do you have high blood pressure? } \\
\hline Yes & $41(41.0)$ & $63(61.8)$ & \\
\hline No & $59(59.0)$ & $35(34.3)$ & .001 \\
\hline Do not know & $0(0)$ & $4(3.9)$ & \\
\hline
\end{tabular}

Values provided as $\mathrm{n}(\%)$.

present study suggests that there might be another explanation for the symptom.

Our results support the hypothesis that patients urinate when they wake up (even if patients do not feel the need to urinate they go to the bathroom anyway) rather than wake up because they need to urinate. $^{9-11}$ Several studies carried out in laboratory settings have suggested that nocturia is more prevalent in patients with OSA ${ }^{12-15}$ and that it may be related to the severity of OSA. ${ }^{10,16-19}$ Prevalence of nocturia in patients with OSA varied in different studies, from $41.1 \%{ }^{12}$ and $47.8 \%{ }^{13}$ up to $64.9 \%{ }^{14}$ and $70 \% .{ }^{15}$ Among studies showing that nocturic frequency relates to the severity of OSA, Kaynak et $\mathrm{al}^{10}$ reported that nocturia of $>3$ times was significantly more reported by patients with severe OSA $(P<.001)$. Endeshaw et $\mathrm{al}^{17}$ also found that the mean number of nocturia episodes among 
community-dwelling older adults increases with severity of OSA, from $1.7 \pm 1.1$ episodes of nocturia in the group with an Apena-Hypopnea Index score of $<10$ per hour of sleep to $2.6 \pm 1.4$ in the group with an Apena-Hypopnea Index score of $\geq 25$ per hour of sleep.

Our data support the possibility that SOSAs are more common among patients who complain of nocturia compared with the general population. In our study, patients with frequent nocturia have higher odds for SOSAs. Pressman et $\mathrm{al}^{11}$ found that $79.3 \%$ of the awakenings from sleep that patients ascribed to their need to urinate were actually a result of apnea, hypopnea, or other sleep disorders. They suggested that OSA patients awaken from their primary sleep disorder and feel the need to urinate. Lowenstein et $\mathrm{al}^{9}$ performed home sleep studies in a small group of urogynecologic patients with nocturia and found that OSA was present in $81 \%$ of women with nocturia, compared with $40 \%$ of the control subjects. Several studies showed improvement of nocturia in patients with OSA after institution of continuous positive airway pressure therapy. ${ }^{16,19-24}$ To explain the possible physiopathologic explanations for this phenomenon, Umlauf et $\mathrm{al}^{25}$ suggest an evoked response to conditions of negative intrathoracic pressure caused by inspiratory effort posed against a closed airway that induces a natriuretic response (release of atrial natriuretic peptide because of cardiac distension). Akashiba et $\mathrm{al}^{26}$ suggested that an abnormal renal function, as seen in patients with OSA, is related to hypoxemia during sleep.

Both BPH and sleep apnea are causes of nocturia and both may be present concurrently. It is hard to say what happens when both are present concomitantly and what is the relative contribution of each.

Table 2. Risk Group Distribution According to the Berlin Questionnaire Results

\begin{tabular}{lccc}
\hline $\begin{array}{l}\text { Risk Group } \\
\text { Category }\end{array}$ & $\begin{array}{c}\text { Comparison Group } \\
(\mathrm{n}=100)\end{array}$ & $\begin{array}{c}\text { Research Group } \\
(\mathrm{n}=102)\end{array}$ & $P$ \\
\hline High risk & $31(31.0)$ & $59(57.8)$ & $<.001$ \\
Low risk & $69(69.0)$ & $43(42.4)$ & \\
\hline
\end{tabular}

Values provided as $\mathrm{n}(\%)$. For the definitions of high- and low-risk groups, see the Methods section. $P$ is based on Pearson's $\chi^{2}$.
Figure 2. Odds ratios for a high risk of symptoms of obstructive sleep apnea (OSA), according to the number of nocturia episodes per night. The $y$ axis is a logarithmic scale.

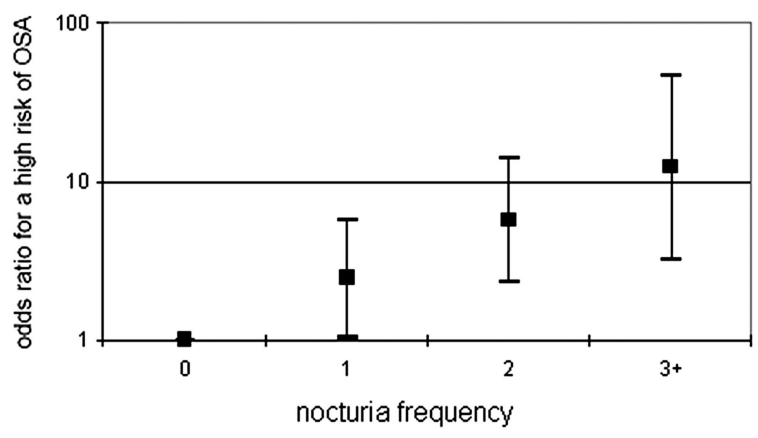

\section{Study Limitations}

The number of patients included in this study was quite small. A relatively large proportion of potentially eligible patients was either unavailable or refused to participate, thus increasing the risk for selection bias. Interviewers were not blinded to the affiliation of each patient to the research or comparison groups. Some overlap exists because there were patients with nocturia once per night in both groups. The Berlin Questionnaire identifies SOSAs and it is not a definitive diagnosis of OSA (as polysomnography). However, the same questionnaire has been used in other studies to identify associations with OSA. ${ }^{4-6,27}$ Only a few background variables were available for participants, ie, age and BMI. The study included only men.

\section{Conclusion}

The odds for reporting SOSAs increase among patients reporting frequent nocturia episodes. Therefore, the diagnosis of OSA should be considered seriously whenever a patient reports frequent awakenings from sleep to urinate, even when the symptom was previously attributed to the presence of BPE.

\section{References}

1. Van Kerrebroek P, Abrams P, Chaikin D, et al. The standardization of terminology in nocturia: report from the standardization subcommittee of the International Continence Society. BJU Int 2002;90(Suppl 3):11-5.

2. Schatzl G, Temml C, Schmidbauer J, Dolezal B, Haidinger G, Madersbacher S. Cross-sectional study of nocturia in both sexes: analysis of a voluntary health screening project. Urology 2000;56:71-5. 
3. Appell RA, Sand PK. Nocturia: etiology, diagnosis, and treatment. Neurourol Urodyn 2008;27:34-9.

4. Netzer NC, Stoohs RA, Netzer CM, Clark K, Strohl KP. Using the Berlin Questionnaire to identify patients at risk for the sleep apnea syndrome. Ann Intern Med 1999;131:485-91.

5. Netzer NC, Hoegel JJ, Loube D, et al. Prevalence of symptoms and risk of sleep apnea in primary care. Chest 2003;124:1406-14.

6. Chung F, Ward B, Ho J, Yuan H, Kayumov L, Shapiro C. Preoperative identification of sleep apnea risk in elective surgical patients, using the Berlin questionnaire. J Clin Anesth 2007;19:130-4.

7. von Oech R. Whack on the side of the head: how you can be more creative. New York, NY: Warner Books; 1990.

8. Tandeter H, Vinson D. Transient discontinuity of care: others seeing what we have missed. J Fam Pract 1998;47:423-4.

9. Lowenstein L, Kenton K, Brubaker L, et al. The relationship between obstructive sleep apnea, nocturia, and daytime overactive bladder syndrome in women. Am J Obstet Gynecol 2008;198:598, e1-5.

10. Kaynak H, Kaynak D, Oztura I. Does frequency of nocturnal urination reflect the severity of sleep-disordered breathing? J Sleep Res 2004;13:173-6.

11. Pressman MR, Figueroa WG, Kendrick-Mohamed J, Greenspon LW, Peterson DD. Nocturia. A rarely recognized symptom of sleep apnea and other occult sleep disorders. Arch Intern Med 1996;156:545-50.

12. Moriyama Y, Miwa K, Tanaka H, Fujihiro S, Nishino Y, Deguchi T. Nocturia in men less than 50 years of age may be associated with obstructive sleep apnea syndrome. Urology 2008;71:1096-8.

13. Hajduk IA, Strollo PJ Jr, Jasani RR, Atwood CW Jr, Houck PR, Sander MH. Prevalence and predictors of nocturia in obstructive sleep apnea-hypopnea syndrome: a retrospective study. Sleep 2003;26:61-4.

14. Plywaczewski R, Stoklosa A, Bednarek M, et al. [Nocturia in obstructive sleep apnoea (OSA).] Pneumonol Alergol Pol 2007;75:140-6.

15. Krieger J, Petiau C, Sforza E, Delanoë C, Hecht MT, Chamouard V. Nocturnal pollakiuria is a symptom of obstructive sleep apnea. Urol Int 1993;50:93-7.

16. FitzGerald MP, Mulligan M, Parthasarathy S. Noc- turic frequency is related to severity of obstructive sleep apnea, improves with continuous positive airways treatment. Am J Obstet Gynecol 2006;194: 1399-403.

17. Endeshaw YW, Johnson TM, Kutner MH, Ouslander JG, Bliwise DL. Sleep-disordered breathing and nocturia in older adults. J Am Geriatr Soc 2004; 52:957-60.

18. Guilleminault C, Lin CM, Goncalves MA, Ramos E. A prospective study of nocturia and the quality of life of elderly patients with obstructive sleep apnea or sleep onset insomnia. J Psychosom Res 2004;56:511-5.

19. Oztura I, Kaynak D, Kaynak HC. Nocturia in sleepdisordered breathing. Sleep Med 2006;7:362-7.

20. Mankowski M, Koziej M, Cieslicki J, et al. [Clinical picture and outcome of conservative treatment for obstructive sleep apnea.] Pol Arch Med Wewn 1995; 93:234-41.

21. Kiely JL, Murphy M, McNicholas WT. Subjective efficacy of nasal CPAP therapy in obstructive sleep apnoea syndrome: a prospective controlled study. Eur Respir J 1999;13:1086-90.

22. Margel D, Shochat T, Getzler O, Livne PM, Pillar $\mathrm{G}$. Continuous positive airway pressure reduces nocturia in patients with obstructive sleep apnea. Urology 2006;67:974-7.

23. Weaver TE, Chasens ER. Continuous positive airway pressure treatment for sleep apnea in older adults. Sleep Med Rev 2007;11:99-111.

24. Liu S, Liu L. [Effect of treatment with continuous positive airway pressure on nocturnal polyuria in patients with obstructive sleep apnea syndrome.] Zhonghua Jie He He Hu Xi Za Zhi 2001;24:158-60.

25. Umlauf MG, Chasens ER. Sleep disordered breathing and nocturnal polyuria: nocturia and enuresis. Sleep Med Rev 2003;7:403-11.

26. Akashiba T, Otsuka K, Yoshizawa T, et al. [Effects of nasal continuous positive airway pressure (NCPAP) on nocturnal renal function in obstructive sleep apnea syndrome (OSAS).] Nihon Kyobu Shikkan Gakkai Zasshi 1991;29:573-7.

27. Singh H, Pollock R, Uhanova J, Kryger M, Hawkins K, Minuk GY. Symptoms of obstructive sleep apnea in patients with nonalcoholic fatty liver disease. Dig Dis Sci 2005;50:2338-43. 